\title{
A ELEGIA EM ROMA: SEXTO PROPÉRCIO
}

\author{
Prof. Dr. Airto Ceolin Montagner (UFRRJ)
}

\begin{abstract}
RESUMO: A literatura latina conhece seu apogeu na época de Augusto. Entre os diversos gêneros cultivados, a elegia, que teve sua origem entre os gregos, ganhou relevância com as obras de quatro poetas, a saber, Cornélio Galo, Tibulo, Propércio e Ovídio. A produção desses poetas permite observar o conjunto da tópica elegíaca latina, principalmente no que ela tem de mais peculiar: o erotismo como experiência pessoal e biográfica do poeta. O amor é visto como paixão, razão de vida e fonte de inspiração. Amor é também doença, páthos, que toma conta do amante em todos os aspectos mais pungentes das suas contradições, ante uma senhora volúvel e incapaz de ser fiel, muito menos uma domina, no conceito da respeitabilidade romana. Sexto Propércio é o poeta elegíaco aqui considerado e através dele é possível analisar criticamente o alcance da poesia elegíaca latina.
\end{abstract}

PALAVRAS-CHAVE: Elegia latina - erotismo - Propércio

\section{THE ELEGY IN ROME: SEXTUS PROPERTIUS}

\begin{abstract}
Latin literature knows its zenith in Augusto's time. Among the various cultivated gener, elegy, which had its origin among the Greeks, gained relevance with the works of four poets, namely, Cornelius Galo, Tibulo, Properce and Ovid. The production of these poets allows us to observe the ensemble of the Latin elegiac topic, especially in what is most peculiar: eroticism as a personal and biographical experience of the poet. Love is seen as passion, reason of life and source of inspiration. Love is also disease, ducks, that takes care of the lover in all the most poignant aspects of his contradictions, before a fickle lady and unable to be faithful, much less a dominates, in the concept of Roman respectability. Sexto Propercio is the elegiac poet here considered and through it is possible.
\end{abstract}

KEUWORDS: Latin elegy - eroticism - Properce.

Sempre que a temática literária sobre um passado que nos parece distante vem ao debate, questiona-se, hoje, seu interesse e validade, já que as coisas mais imediatas nos parecem mais úteis e atraentes. As respostas mais constantes a tal pergunta podem ser 
de ordem cultural, lembrando que o passado molda o presente, que retrata um momento da evolução da experiência humana ou, ainda, que seu objeto vale por si mesmo no contexto da história da literatura. Mas a melhor resposta a esta questão será o escopo deste trabalho, pois aqui retomamos o gênero literário da elegia, revisitando sua origem e desenvolvimento, sua temática e sua forma no contexto em que ela se desenvolve na Roma da época de Augusto, já que ela permeia o lirismo que então florescia. Traçaremos seu retrato através de um dos mais renomados entre os autores elegíacos.

Heinrich Lausberg (1962, p. 20), ao falar sobre os diferentes tipos de discursos, destaca que o discurso litúrgico é aquele que permanece para ser repetido de ano a ano ou conforme os ritmos do tempo. O discurso litúrgico é de uso repetido e representa, fenomenologicamente, aquilo que "liberto de sua ligação ao ritmo litúrgico do tempo, se chama poesia ou a bela literatura". Nisto se opõe ao discurso pragmático que, ao cumprir sua função, esvai-se no interior da sua consumptibilidade. Assinala ainda o estudioso alemão que uma das tarefas do filólogo, além daquela de salvar os textos da destruição material, é a de transmiti-los à memória das gerações vindouras, no papel de professor, ou, ainda, intensifica-los de maneira aviventadora na tradição. Disso decorre a crítica textual e a crítica literária, para que seja mantido o verdadeiro sentido do texto em seu devido contexto de produção, já que a situação cultural modifica-se com o passar dos anos. Esta ideia é a seiva que nutre o presente empenho, uma vez que reaviva o interesse pelo canto elegíaco.

A elegia latina, como os demais gêneros literários (exceto a sátira), é de origem grega. Carlini (2005, p 22) expõe que a elegia é a primeira forma lírica que floresceu na Hélade. Sua forma era o dístico elegíaco, composição formada de um hexâmetro e um pentâmetro. Ela constitui um elo entre a épica e a lírica propriamente dita, haja vista a estrutura métrica. Quando ao conteúdo, o lirismo dá desafogo à manifestação do sentimento individual e à expressão dos afetos humanos. Sinteticamente, pode-se dividir o lirismo da literatura grega em quatro subgêneros: a elegia, a jâmbica, a mélica monódica e a coral.

Etimologicamente, a palavra é formada de dois termos: elegeíon (referindo-se à natureza do metro) e élegos (canto lúgubre). No princípio, seu argumento era triste, depois adquiriu caráter guerreiro, com Calino e Tirteu, ampliou-se para poesia civil e política, com Sólon, erótico com Mimnermo de Colofone, gnômico e sentencioso, com Xenofonte, Teógnis e Focílides. O instrumento que acompanhava o canto elegíaco era a flauta (gr. aulós, lat. tíbia). Tais textos elegíacos eram cantados no simpósio, lugar de 
encontro para os intelectuais e os aristocratas, sendo a principal forma de comunicação e de discussão sobre a pólis até o advento do teatro.

Os poetas latinos indicaram claramente seus modelos gregos, adotaram o gênero, mas renovaram-no dando-lhe características específicas: tornou-se o verso em que se expressavam os sentimentos amorosos, embora também fosse usada por ocasião das expressões de luto, nas lamentações fúnebres, donde a associação da elegia ao pranto, também um lugar comum (topos). Diferentemente da grega, a elegia latina é um canto de caráter subjetivo e autobiográfico, ao passo que a grega mitiga o subjetivismo. A elegia latina, declaradamente autobiográfica, insiste em proclamar o seu embasamento na experiência subjetiva do poeta; tende, na realidade, a enquadrar cada uma das experiências em formas e situações típicas, segundo modalidades recorrentes. Pode-se falar de um universo elegíaco, com papéis e comportamentos convencionais, e de um código ético seu, de uma ideologia agregada em volta dos seus valores básicos.

$\mathrm{Na}$ fase helenística, Antímaco de Cólofon retomou o verso elegíaco, dedicando seus cantos a Lyde, sua amada prematuramente falecida: cantava experiências míticas de amores perdidos tragicamente. Os alexandrinos modificaram a elegia, deixando de lado o conteúdo exortativo para focalizar narrações de amores do mito, de preferência aqueles mais rebuscados e pouco conhecidos. Exemplo disso é Filetas, que imitou Antímaco, homenageando a amada Bítis; do mesmo modo Hermesianates cantou Lêmcio, relatando uma série de amores infelizes para demonstrar o poder de Éros. Todavia o maior poeta alexandrino foi Calímaco que, em seus Aitia, "Origens", homenageou o nascimento dos ritos das instituições e tradições religiosas que tiveram os heróis como protagonistas.

Os romanos, por sua vez, retomaram o verso elegíaco, mas trataram de dar-lhe um novo conteúdo, incluindo seus amores pessoais, instituindo a elegia como poesia de amor, cabendo aos demais versos líricos os conteúdos diversificados. O amor é tomado sob a ótica do sofrimento, como páthos, doença, seja porque o poeta não encontrava correspondência por parte da pessoa amada, seja porque o ciúme afetava a relação, ante a infidelidade da amada.

A elegia latina é, antes de tudo, uma poesia de amor, visto que o amor, para o poeta, é a experiência única e absoluta que enche sua existência e lhe dá sentido; é a "perfeita forma de vida" escolhida por ele, a qual se contrapõe aos demais modelos éticos, proclamando a sua superioridade e a atingida autárkeia, a satisfatória autossuficiência, divulgada pelas filosofias da época. A vida do poeta elegíaco, toda dedicada ao amor, 
configura-se como servitium amoris, como escravidão diante da domina, caprichosa, tirana e infiel. Esta relação vem tratada como uma milícia (escravidão / serviço militar) em favor de Amor. A realização desse amor é feita de raras alegrias e de muitos sofrimentos (além de trair e de enciumar o amante, a amada o põe na situação típica do paraklausítron, na qual o enamorado rejeitado lamenta diante da porta a crueldade da amada). O poeta então, irremediavelmente massacrado pela paixão, abandona-se a uma espécie de agradável aquiescência da dor, a uma vontade de sofrer (ocasionalmente lhe ocorre um gesto de rebelião: é a situação da renuntiatio amoris). As amarguras e as contínuas desilusões levam-no, por vezes, a projetar sua própria experiência no mundo puro do mito ou na feliz inocência de uma idade do ouro para sublimá-la, assimilando-a aos amores heroicos da literatura, transferindo-a para um universo ideal e plenamente satisfatório; o mito é, pois, uma forma de evasão. Prisioneiro de um amor irregular, de uma paixão alienante e infamante, o amante pratica uma vida de nequitia, de “degradação', de “dissipação”, visto que todos o teriam julgado sem qualidades positivas: ele repudia seus deveres de civis, os valores gloriosos do cidadão soldado, contrapondo às durezas da guerra a languidez amorosa; desta esfera transfere todo o seu empenho moral para uma direção absoluta: herói, não de guerra, mas de amor.

É singular o fenômeno pelo qual a elegia, declaradamente rebelde aos valores consolidados pela tradição, ao mos maiorum, de fato recupera aqueles valores, transformando-os no próprio universo. Veremos então que a relação amorosa, "institucionalmente" irregular (envolve só cortesãs e mulheres "libertas", nunca as da sociedade respeitável), tende a configurar-se como liame conjugal, vinculado pela fides, salvaguardado pela pudicitia, desconfiando da luxúria e do refino urbano.

Nesta espécie de boêmia que é a vida do poeta elegíaco, as razões do amor e da atividade poética identificam-se, delimitam o próprio universo: poesia que nasce da experiência direta do poeta amante, poesia que parece com sua vida, deve ao mesmo tempo dispensar uma função prática, mas servir como meio de galanteio, cooperar para seduzir a amada com a perspectiva da fama e de uma glória imortal que a poesia lhe confere.

Na época de Augusto, o gênero elegíaco teve curta duração, porém floriu de forma intensa. Segundo Perutelli et alii, há duas teorias sobre sua procedência: a primeira delas mira sua ascendência nos poetas helenísticos, onde teriam existido elegias de amor, compostas por vários poetas, com uma linguagem repleta de comparações mitológicas, embora não haja muitos textos remanescente que comprovem isso; a 
segunda propõe que a elegia tenha sido uma criação original latina, desenvolvida a partir do epigrama alexandrino, muitas vezes dedicados ao amor. O certo é que, em Roma, a elegia adquire características específicas, tornando-se basicamente poesia de conteúdo amoroso, altamente subjetiva, seguindo regras e convenções precisas, também unificadoras de todos os poetas augústeos. Ao mesmo tempo, persiste uma tradição latina que começa com a tormentosa história de amor por Lésbia, celebrada por Catulo, avançando entre os demais autores como um cliché de amores infelizes, com mulheres de nome grego, talvez associadas a figuras de mulheres casadas ou de vida irregular no contexto social de então. No entanto, os poemas de Catulo para Lésbia não são elegias. Aponta-se que foi a obra de Cornélio Galo que fez a passagem de uma poesia míticoerudita (presente entre os helenistas e os poetae novi) para uma lírica subjetiva e autobiográfica, cuja maior expressão está no erotismo lânguido de Tibulo, no apaixonamento de Propércio, em seu sentimento por Cíntia, e na genialidade artística de Ovídio.

As obras de Cornélio Galo foram perdidas para nós, mas ele, um homo novus de família provavelmente da classe equestre, teria sido o iniciador do gênero em Roma, estabelecendo convenções para a elegia. Sua obra Amores, em quatro livros, dos quais há poucos versos remanescentes, canta os sofrimentos provocados por sua amada Licor. Galo introduziu elementos autobiográficos, subjetivos e pessoais, os quais marcaram presença também na obra dos poetas consequentes, como Tibulo e Propércio, criando uma espécie de lugar comum da elegia latina. Dele também decorre a ideia de nequitia, provocada pela infidelidade da amada, tópica já presente em Catulo e nos demais elegíacos posteriores.

Conte e Pianezzola (1995, p. 575, v 2) apontam que foram quatro os poetas elegíacos latinos: Cornélio Galo, Tibulo, Propércio e Ovídio. Todos eles tem em comum as convenções da elegia erótica e o devotamento a uma mulher amada. Cornélio Galo cantou o amor sofrido por Licóris, Tibulo sofreu por Délia, Propércio por Cíntia e Ovídio por Corina. Acredita-se que o nome escolhido da amada seria o título da coletânea, já que entre os alexandrinos esse era o procedimento. Possivelmente ele também ocultava a figura da mulher real, mantendo, convencionalmente, o mesmo número de letras do nome real.

Escolhemos o poeta Sexto Propércio para exemplificar, a seguir, o gênero em sua época mais relevante para a poesia lírica latina. 


\section{Lúcio Sexto Propércio / Lucius Sextus Propertius (entre 49 e 47 - 16 ou 15 a. C.)}

Sexto Propércio nasceu na Úmbria, talvez em Assis, entre 49 e 47 a. C., de família abastada, da classe equestre. Sofreu muito, primeiro com o confisco das suas terras para serem distribuídas aos veteranos da guerra de Filipos e depois com lutos por causa da guerra da Perúgia (revolta dos proprietários de terra, reprimida por Augusto em 40-41). Ficou órfão de pai muito jovem. Foi mandado para Roma pela mãe para que tivessse uma boa educação e seguisse a carreira forense, mas a vocação poética falou mais alto. Segundo Albert (1827-1880), cap. IV, "Le nom de Tibulle appelle celui de Properce. Les deux poètes étaient du même âge, ils sont morts à peu près en même temps; ils ont chanté les mêmes sujets. Properce ne fut même pas tenté d'aborder la vie publique; il ne s'attacha point à un patron illustre, il ne songea point à servir dans les armées; et de bonne heure "Apollon lui interdit de faire entendre sa voix au forum."

Inseriu-se nos círculos mundano-literários da capital. Sua elegia gira em torno de Cíntia, uma cortesã de alta classe, bela, culta e atrevida. Segundo Perutelli, Apuleio a identifica com Hóstia na vida real, a qual talvez fosse descendente de Hostius, um poeta da época dos Gracos e autor de Bellum Histricum; esta é uma dedução de Apuleio, baseado numa afirmação de Propércio, em III, 20, 8: splendidaque a docto fama refuget avo (brilha pela esplêndida fama de um douto avô). Outro evento importante da sua vida foi a aproximação do círculo de Mecenas, em 28 a.C., após a publicação de um único livro de elegias de amor, até então. Mecenas tentou orientá-lo para os temas da ideologia Augústea, mas o poeta declarou-se inapto para a poesia épico-histórica. Nos anos sucessivos, publicou outros três livros de elegias. Conheceu e admirou Virgílio, professando seu apreço pelo poema da Eneida, pois foi ele quem anunciou a obra num famoso dístico: "Retirai-vos, poetas romanos, retirai-vos, poetas gregos: vai nascer não sei que coisa maior do que a Ilíada"(II, 31). Todavia seu elo de ligação mais profundo foi com Ovídio, para quem lia seus poemas. Conheceu também Horácio. Talvez tenha casado e gerado um filho que, segundo Plínio o Jovem, era o poeta Paulo Propércio. Sua relação com Cíntia durou cinco anos, quando houve a separação, mas teria continuado posteriormente até a morte da mulher (20-19 a.C.). Pouco tempo depois, por volta dos 35 anos, encerrou sua breve vida, provavelmente em 16 a.C.

\section{Obras de Propércio:}

Restaram quatro livros de elegias de Propércio, escritos em datas hoje não bem definidas. Acredita-se que o primeiro livro tenha sido publicado em 28 a.C. Não há 
notícias seguras sobre o segundo e o terceiro; o quarto teria sido publicado postumamente. Veremos abaixo, de modo geral, o conteúdo das elegias.

\section{Livro I:}

O Primeiro livro contém 22 elegias, das quais 10 são dedicadas a Cíntia e 12 a amigos (nomeados como Tulo, Galo, Basso e Pôntico) e rivais. Os poemas são de tamanho variado, entre dez e cinquenta versos, totalizando cerca de setecentos versos.

O Livro I começa com o nome Cíntia, o que faz supor que esse também pode ter sido o título do livro, pois, conforme a tradição dos poetas gregos, dava-se o nome da mulher amada a esse tipo de coletânea. Direta ou indiretamente, todos os poemas estão relacionados a Cíntia, mulher culta e refinada, cujo fascínio domina a vida do poeta. Se Propércio é considerado um poeta complexo, o livro I é, então, o menos properciano de todos, embora já contenha os temas fundamentais de sua poesia. Na elegia I: Cynthia prima suis miserum me cepit ocellis (Cíntia foi a primeira A raptar-me com seus belos olhos, infeliz de mim...), já determina a temática do servitium, caracterizado como a escravidão amorosa do poeta, sempre submisso à amada, ainda que com lamentos e reprovações pela infidelidade da sua senhora. Seu destino é amar sempre. Por isso sofre dolorosamente, impondo-se a uma vida de nequitia (dissipação, dissolutez, degradação social), em confronto com a dignidade humana e com sua condição social. Sua recusa aos valores do mos maiorum e aos valores da civitas, como já o fizera Catulo, contrapõe-se aos modelos éticos dominantes, implicando uma aceitação dos seu destino: "Muitos morreram felizes num amor durável. Entre esses, a terra cubra também a mim. Nasci não para a glória, nem para as armas: é esta a milícia que o destino me assegura". Torna-se com isso um miles, um soldado nos embates de Amor. Cíntia, mesmo sendo uma mulher elegante, refinada e cheia de cultura literária e musical, vivia no submundo de Roma, frequentado por homens de diversas origens. Ligar-se a uma mulher assim, mundana, significava comprometer-se socialmente e contrariar o código da respeitabilidade a que um homem da sua condição estava predestinado. Há um elo contínuo entre o sofrimento amoroso e a produção poética. A poesia é um desafogo à sua dor e, ao mesmo tempo, o único meio para alcançar os favores da amada, já que não era rico, mas ela, podemos supor, amava bastante o dinheiro. Para ele, a poesia amorosa é mais importante do que os gêneros considerados mais elevados: 
No amor, mais vale o verso de Mimnermo do que o de Homero;

Amor, que é pacífico, requer versos tênues.

A recusa aos gêneros elevados e sua escolha por um estilo de vida está nitidamente ligada ao seu itinerário poético. A preferência por uma arte tênue, refinada e delicada, produz uma poesia que se dirige à mulher amada, a domina cruel, ao passo que o poeta, que sofre por amor, define-se como miser. Todavia, a degradação a que o poeta se condena, abandonando a carreira e o decoro social, é motivo de orgulho, uma vez que esta relação maldita configura-se como servitium, servidão em que o poeta se compraz com o sofrimento, pois o amor está no centro da vida, como razão para sua existência: "Só tu, Cíntia, és para mim a família e os pais, tu, todo momento de alegria" (I, 11, 23). Nos confrontos com a amada infiel, o amor não comparece como libertinagem ou como aventura galante, mas como uma relação ideal: sonha para ambos os amores do mito, paixão exclusiva e eterna, até a morte. Para tanto, admira os modelos e valores da tradição, desejando um amor visto como foedus (pacto), uma ligação assegurada pelos deuses e substanciado pela castitas, pudor e fides, princípios éticos das matronas. Todavia, a realidade é bem diversa: o poeta consome-se na contradição da qual é prisioneiro, pois é seduzido pelo fascínio, pela elegância mundana de sua domina ao tempo em que procura nela simplicidade, dedicação absoluta e fidelidade. Desta sua grande insatisfação nasce a necessidade de fuga, de evasão no "mundo do puro mito: 'transfigurados' em personagens míticas, o poeta apaixonado e a sua senhora viveriam amores exemplares, incontamináveis sonhos" (Conte e Pianezzola, v. II p 578).

Não se percebe no livro I nenhum aceno à poesia civil ou às ações políticas do regime de Augusto. O acento autobiográfico predomina. Nas elegias II e III, o poeta convida a amada a deixar de lado o luxo e acredita ser o dono de seu coração, ao passo que na elegia IV torna-se escravo de sua senhora; na elegia XI, manifesta seu ciúme pela estada da amada em Baia, lugar apontado por Cícero como antro de corrupção; reprova sua indiferença na elegia $\mathrm{XV}$, mas teme sua fuga para a Ilíria com outro amante, na elegia VIII. Persistindo em seu amor: "Cíntia foi a primeira e Cíntia será a última", conforme declara na elegia XII. Na elegia XVII, pensa sobre a amada durante uma tempestade; na elegia XVIII, distante de Roma, evoca novamente a amada, chamando como testemunha da sua fidelidade os pássaros e as árvores. Na mesma ocasião, na elegia XIX, fantasia sobre sua morte e acredita que Cíntia derrame muitas lágrimas. A 
elegia XXI retrata as palavras de um moribundo durante o Bellum Perusianum. Na última elegia do livro I (XXII), declara ter nascido na Úmbria, e recorda a guerra civil.

\section{Livro II:}

O segundo livro, dedicado a Mecenas, contém 34 elegias e foi publicado em 25 a.C. Sua poesia torna-se mais complexa, fundindo paixão e intelecto. $\mathrm{O}$ amor continua em primeiro plano, protagonizado por Cíntia. Na elegia I, o poeta dirige-se a Mecenas para exercer sua recusatio, recusa à poesia épico-histórica, afirmando que a escolha por seu modo de vida e de poesia de amor decorre da puella, sua única fonte de inspiração: "Non haec Calliope, non haec mihi cantat Apollo: ingenium nobis ipsa puella facit" “Dita-me isto não Calíope, nem Apolo: a inspiração me é dada pela donzela". (II, I, v 3 e ss). No livro II, predominam os temas eróticos (a beleza de Cíntia, queixumes, protestos e acusações pela infidelidade da amada, alegrias pela felicidade de amar Cíntia, presença do amor e da morte). Seu modelo é Calímaco e Filetas, que alienam a poesia de todo empenho político. Uma existência dedicada ao otium e ao servitium torna-o uma coisa só com a atividade literária do poeta amante, pois tira da vida a matéria poética. É no livro II que o poeta inclui a mitologia erudita, introduzindo mitos rebuscados, conforme o modelo alexandrino. Nas elegias II, 2 e 3, o poeta exalta a beleza da amada e, a seguir, lamenta-se da sua crueldade e da sua leviandade (II, 4 e 5). A elegia II, 15, segundo Mariotti (1989, p 377), é um exemplo de que a arte de Propércio tornou-se mais densa e difícil; começa com um grito de alegria pela noite "luminosa" e o "doce leito" que o tornam feliz no amor: $O$ me felicem! O nox mihi candida et o tu / lectule, deliciis facte betate meis! (Ó, sou feliz! Ó noite luminosa e ó tu / leito tornado feliz para minhas delícias!). Em II, 16, manifesta seu ciúme pelo retorno da Ilíria do seu rival e protetor, e pelas viagens de Cíntia para Preneste, Tívoli e Tusco (II, 31). Nas elegias II, 13, 14 e 15, manifesta seu júbilo pela reconciliação; em II, 8 e 9 deseja a morte porque foi abandonado pela amada e decide esquecê-la (II, 11). Há ainda no livro II elegias de outro assunto, além de Cíntia e seu amor: é o caso da elegia I, com a recusasio; a elegia II, 31, celebra a inauguração do pórtico de Apolo no Palatino e na elegia II, 31, faz o elogio da poesia amorosa e proclama Virgílio como o único digno de celebrar os feitos de Augusto.

\section{Livro III:}

O terceiro livro contém 25 elegias, nas quais o amor por Cíntia se alterna com outros temas. O livro inicia com três elegias que reforçam sua ligação com a temática calimácea. Mais uma vez, recusa adesão à poesia épica (III, 9), proposta por Mecenas. 
Em relação a Cíntia, doce lhe parece o litígio, pois a cólera da amante é sinal de amor (III, 8), todavia amor e dor sempre andam de mãos dadas. A amada tem ciúme do poeta (III, 6), obrigando-o a encontrá-la em Tívoli à noite. (III, 16). A propósito das traições de Cíntia, narra a história da casta Penélope; se deseja retomar seu desespero, relembra que Hemon que, tendo perdido sua Antígona, entregou-se à morte; Aquiles, privado de sua Briseide, deixa os gregos serem massacrados. Acusa Rômulo de ter dado mau exemplo raptando as sabinas. Percebe-se que todas essas lembranças mitológicas não são mero ornamento, mas a própria pintura.

Mariotti (1996, p 378-9) assinala que Propércio não é apenas lamentoso, mas também mostra sua veia cômica quando se dirige a um rival que deveria suportar para sempre um sogro e ter em casa também a sogra (III, 8 v 38). Graciosa também é a elegia III, 23 que alude à perda da tabuleta de cera nas quais Cíntia lhe envia mensagens; outro verdadeiro gracejo é a elegia III, 14, tratando ironicamente sobre as mulheres espartanas que se exercitavam nuas, o que não acontecia em Roma. Todavia, esse jogo literário oscilante, que confronta o cômico e o amoroso, não permite que seja posto de lado o sentimento de amor: são os tolos e os hipócritas que não sabem rir dos valores mais elevados. Em III, 24, Propércio manifesta seu sonho de ter Cíntia somente para si, desejando que o encanto de dias felizes nunca tivesse fim. Que a paz e a alegria não fosse jamais perturbada. Propércio aproxima-se de Catulo quando deseja para a amada um pacto de fidelidade, um foedus nupcial (III, 20); assim, pacis Amor deus est (Amor é um deus de paz) que lhe permitiria viver a velhice dedicada ao estudo da natureza (III, 5). A realidade, todavia, é bem diversa. O poeta procura consolo para as traições no vinho; em III, 17, invoca Baco para que afaste sua imensa inquietude. Há um momento em que o poeta deseja afastar-se da amada definitivamente, como em III, 21, quando planeja uma viagem à Grécia para tornar o espírito mais suportável, pois a distância e o tempo podem abrandar as chagas abertas em seu coração. A este ponto, a relação amorosa caminha para o fim e o livro se conclui com um adeus a Cíntia. Esvai-se o sonho e a ilusão de uma Cíntia idealizada poeticamente, surge a verdadeira, vista como é: A elegia III, 25, 11 e ss. mostra isso com clareza:

Toda aquela fidelidade à tua beleza é falsa, ó mulher! O tempo torna muito diversa a admiração dos meus olhos.

Foi meu amor que te atribuiu tão grande apreço.

É vergonhoso para mim que te distinga entre todas através dos meus versos. Frequentemente eu te louvei pela mutável natureza da tua beleza, a tal ponto que o meu amor te considerava aquilo que na realidade não eras; 
comparei muitas vezes o teu colorido com o da aurora cor de rosa, enquanto o esplendor do teu rosto era fruto de artifício.

Deste mal não conseguiram livrar-me os meus paternos amigos... Mas te alcance a tarda idade, se não obstante os anos te alcançarem e haverão de acrescentar pálidas rugas sobre a tua beleza!

Possas tu, então, desejar arrancar pela raiz os teus cabelos brancos, quando o espelho, ai!, reprovar o teu rosto rugoso,

e, uma vez repelida, suportarás o altivo desprezo,

e, velha, te lamentarás por sofrer o que há um tempo infligiste.

A minha página prediz a tua funesta sorte:

aprende a temer o destino da tua beleza.

Observa-se ainda, no fragmento acima, um lugar comum (tópos) da elegia amorosa: a antevisão de um destino funesto da amada ante a velhice como castigo por ter abandonado o amado.

A par da elegia amorosa, observam-se, no livro III, poemas que se aproximam da poesia gnômico-didascálica, próxima, portanto, dos temas que Mecenas propunha aos membros de seu círculo.

\section{Livro IV:}

O livro IV é composto de 11 elegias, proporcionalmente mais longas do que as dos livros anteriores; manifestam maior integração com a política cultural do regime augústeo, mas sem renunciar à poética calimácea. Cíntia comparece ainda em duas elegias, mas com força reduzida e tratamentos irônicos, porém de arguta leveza; na elegia IV, 9, Cíntia lhe aparece em sonho como uma sombra no reino dos mortos. Liberto da paixão amorosa, desvincula-se da poesia erótica, mas não se torna adepto da poesia épico-histórica, porém segue o autor dos Aitia, tornando-se o indagador das causas, cantando as origens dos nomes, dos mitos e dos cultos de Roma.

$\mathrm{Na}$ elegia 1, descreve em primeira pessoa as origens de Roma e proclama-se o Calímaco Romano - o astrólogo Hóros revela o contraste entre as ambições de Popércio e a natural vocação para a poesia erótica. Na elegia 2, narra a história do deus etrusco Vertumno, capaz de mudar-se em variadas formas e de criar todos os mistérios - à época, fora colocada no Foro uma estátua dele. A elegia 3 revela certa proximidade com a poética ovidiana: a Nereida Aretusa endereça uma carta ao marido distante, Lico. A elegia 4, narra a lenda da virgem Tarpeia que, por amor de Tito Tácio, trai Roma. Embora seja um poema de certo empenho político, não falta nele o páthos lírico característico de suas poesias de amor. Na elegia 6 , por sua vez, celebra a batalha de Ácio e a construção do templo de Apolo no Palatino. A lenda de Hércules, fundador do culto da Ara Maxima e da sua vitória sobre Caco, vem contada na elegia 9. São cinco os 
poemas chamados de elegias romanas, dado que tratam de lendas, monumentos antigos e episódios da história romana. A elegia 10 celebra o santuário de Júpiter Ferétrio, onde Rômulo, Cornélio Cosso e Cláudio Marcelo consagraram os espólios de um comandante inimigo abatido por eles. Na última elegia (11), Cornélia, enteada de Augusto e mulher de Lúcio Emílio Paulo, morta em 16, relembra sua virtuosa vida de esposa e mãe dedicada e convida o marido a chorar novamente por ela. Há duas elegias que retomam o tema amoroso de Cíntia a qual, após sua morte, lhe aparece em sonho para dizer-lhe que seu amor continuava no além tumba (elegia 7). Deste modo, sua poesia de amor enriquece-se com novos motivos, como a revitalização do éros conjugal e a exaltação dos afetos familiares e das virtudes domésticas.

A poética de Propércio surge de uma síntese de diversos elementos culturais, presentes por influência do epigrama e da elegia helenística. Não lhe falta a lembrança dos neotéricos, de Catulo e Cornélio Galo. Sua originalidade consiste na fusão completa entre a elegia romana e a alexandrina: mitos e elementos autobiográficos se unem numa obra de perfeita harmonia. Se a elegia alexandrina era prevalentemente de mitos eruditos, a obra de Propércio surge de uma autêntica experiência amorosa realmente vivida. Trata-se de um apaixonado e exclusivo amor, que se identifica com a própria vida do poeta, efluindo disso o gosto pela erudição e pelo grandioso refino formal. Delineando uma história psicologicamente verdadeira, realiza múltiplas concessões à erudição mitológica e convenções literárias. Não lhe faltam os tópicos fundamentais da elegia amorosa como a paixão, os caprichos da amada, os ciúmes, os encontros e desencontros. As situações assumem um acento sensual e dramático, no qual se revela uma tonalidade densa e impetuosa da escritura.

A língua e o estilo de Propércio deu-lhe a fama de ser um poeta difícil e, por vezes, obscuro. “... il suo stile si caratterizza per la concentrazione, la densità metaforica, la sperimentazione costante di nuova possibilità espressive (... o seu estilo se caracteriza pela concentração, a densidade, a experimentação constante de novas possibilitades expressivas) (Conte \& Pianezzola, 1993, p 580, v 2). Ressaltam esses autores a herança de Calímaco, principalmente na mitologia e na refinada consciência literária, presente na iunctura insólita e metáforas ousadas, bem como na estrutura sintática complexa, não raro conduzindo à obscuridade. Tal fato costuma ser atribuído à condição a que chegaram os manuscritos, com suas lacunas, corruptelas etc. Alia-se a isso o pensamento que não segue um desenvolvimento lógico entre um poema e o consequente, dando a impressão de que algumas elegias sejam a transposição de temas 
isolados, segundo o impulso imprevisível de seu espírito. A linguagem também é árdua, alusiva, rica de significados, com escassas palavras do quotidiano, preferindo palavras raras e preciosas, grecismos, tanto lexicais quanto sintáticos. Realiza algumas concessões à linguagem familiar, como o uso de diminutivos (auricula, asellus, lectulus, ocellus) nas elegias mais realísticas, cujo intuito era caracterizar o tom. Segundo Mariotti, “... a renúncia à banalidade linguística, a erudição mitológica, o uso frequente da apóstrofe são outros meios que servem para tornar elevada a linguagem da elegia..." (Mariotti, 1996, p 385).

Uma leitura da obra de Propércio seguramente proporciona uma visão perfeita da experiência elegíaca mais elevada da literatura latina e, talvez, na literatura universal. Ao mesmo tempo é um documento do pensamento da época em que foi escrita, sendo também um modelo de expressão. Trazê-la de volta através de considerações certamente muito gerais foi nosso intento neste trabalho.

\section{Bibliografia}

CARLINI, Paolo. Sintesi di storia dela letteratua latina. Calvizzano, It. 2005.

CITTI, Vitorio; CASALI, Claudia; GUBELLINI, Maura; PASETTI, Lucia; PANNESI, Antonella. Candidi soles: dalle origini al tardo antico. Bologna: Zanichelli Editore S.p.A., 2012.

CONTE, Gian Biagio, PIANEZZOLA, Emílio. Storia e testi della letteratura latina. Milano: Le Monier, 1995, v. 2

GARBARINO, Giovana. Storia e testi della letteratura latina. Milano: Paravia Bruno Mondadori Editori, 2001.

HERZOG, Reihardt \& SCHMIDT, Peter Lebrecht. Nouvelle histoire de la littérature

Latine. Version française sur la direction de François Heim. Paris: Ouvrage publié avec le concours du Centre National de la Recherche Scientifique; Bonn: de Inter Nationes, 200, v. 4

LAUSBERG, Heirich. Linguística românica. Tradução de Marion Ehrhardt e Maria Luísa Shemann. 2 ed. Lisboa: Fundação Calouste Gulbenkian, 1962.

MARIOTTI, Italo. Letteratura latina: storia e testi. Bologna: Nicola Zanichelli S.p.A., 1989. 